\title{
MIGRAÇÃO E VIOLÊNCIA: O PODER DOS ATORES NÃO ESTATAIS VIOLENTOS NA DINÂMICA DOS PROCESSOS MIGRATÓRIOS EM REDE
}

\section{MIGRATION AND VIOLENCE: THE POWER OF VIOLENT NON- STATE ACTORS IN DYNAMICS OF NETWORK MIGRATION PROCESSES}

\author{
${ }^{1}$ Maria Luiza Roman Folle \\ ${ }^{2}$ Giovanni Olsson
}

\section{RESUMO}

Na medida em que guerras, epidemias, perseguições e catástrofes ocorrem, milhões de pessoas são impulsionadas a viverem em condições transitórias. A inserção dos atores não estatais violentos no protagonismo do processo migratório foi alicerçada pela poderosa rede, alimentada pela globalização e instrumentalizada para garantia da ilusão coletiva de ordem pública gerenciada pelo Estado. O processo migratório em rede, amoldado pelo poder político dos atores não estatais violentos, demonstra-se como um eficiente instrumento de passagem de fluxos, e é utilizada para expansão de poder político e práticas voltadas ao enriquecimento ilícito.

PALAVRAS-CHAVE: Atores não estatais violentos; poder político; processos migratórios; rede

\begin{abstract}
Insofar as wars, epidemics, persecution and disasters occur, millions of people are driven to live in transient conditions. The inclusion of non-state actors in violent role of the migratory process was underpinned by the powerful network, fueled by globalization and instrumentalized to guarantee the collective illusion of public policy managed by the state. The networking migration process, dented by the political power of non-state violent actors is demonstrated as an efficient flow passage instrument, and is used for expansion of political power and practices aimed at illicit enrichment.
\end{abstract}

Keywords: Non-state violent actors; political power; migration processes; network

\footnotetext{
${ }^{1}$ Mestranda em Direito pela Universidade Comunitária da Região de Chapecó - Unochapecó, Santa Catarina, SC, (Brasil). E-mail: malufolle@ hotmail.com.

${ }^{2}$ Doutor em Direito e Professor Permanente na linha Atores Internacionais do Programa de Mestrado em Direito da Universidade Comunitária Regional de Chapecó - Unochapecó, Santa Catarina, SC, (Brasil). E-mail: gio.olsson@desbrava.com.br.
} 


\section{INTRODUÇÃO}

O presente artigo estuda os atores internacionais não estatais violentos e como estes se utilizam do processo migratório em rede para expandir seu poder através do exercício de uma governança paralela à estatal e, ainda, para a promoção do próprio enriquecimento ilícito. A importância do tema se justifica por sua considerável contemporaneidade, ainda mais porque a migração constitui um fenômeno social que se manifesta diariamente no espaço global, de modo que seu estudo se mostra necessário e relevante para compreender a leitura atual da realidade.

O objetivo geral da presente pesquisa consiste em analisar qual a influência do poder no processo migratório em rede dos atores não estatais violentos e suas consequências. Especificamente, a presente pesquisa tem como tarefa descrever as características dos atores internacionais não estatais violentos; estudar de que forma ocorre o processo de migração em rede; e, por fim, compreender o poder no processo de migração em rede e seus reflexos e impactos.

A migração é responsável pelos grandes fluxos globais de pessoas e tornou-se presa fácil para os atores não estatais violentos, que, através do processo de redes, expandem seus negócios ilícitos, promovendo um poder econômico capaz de influenciar e limitar a soberania estatal.

Inicialmente, a atenção é dedicada para a compreensão das características dos atores não estatais violentos, suas estratégias de atuação e o impacto de suas ingerências no cotidiano da sociedade. Na sequência, estuda-se o processo migratório em rede, as teorias da migração, na figura do emigrante/imigrante, as manifestações da rede e sua contribuição para o protagonismo dos atores não estatais violentos.

Por fim, o estudo volta-se para o questionamento e as perspectivas de reflexão que possibilitem a compreensão de paradoxos internacionais contemporâneos, que assolam paradigmas, instituições, conceitos e fundamentações, a partir da influência do poder dos atores não estatais violentos no espaço global.

A metodologia adotada no presente artigo consiste no método dedutivo, sendo a pesquisa de caráter qualitativo. Como técnica de pesquisa, foi utilizada a pesquisa 
bibliográfica, a partir de obras nacionais e estrangeiras, com a finalidade de investigar as hipóteses aventadas.

\section{ATORES INTERNACIONAIS NÃO ESTATAIS VIOLENTOS NA SOCIEDADE INTERNACIONAL}

$\mathrm{O}$ até então intacto estatocentrismo do Estado soberano, a partir do século XX, viu-se ameaçado pela própria evolução dinâmica da sociedade, porque o surgimento de atores não estatais transnacionais e a amplitude do mercado globalizado passaram a limitar sua capacidade tradicional, enfraquecendo tal condição (OLIVEIRA, 2014, p.33).

$\mathrm{Na}$ atmosfera política globalizada, ator internacional é o agente que atua, influencia e se relaciona mutuamente na dinâmica da sociedade internacional, seja em ações de cooperação, seja em ações de conflito, com intuito de cumprir funções e objetivos propostos pelo próprio sistema. A capacidade, a autonomia, as habilidades, o poder de influência e as tomadas de decisões são exemplos de determinantes que categorizam os atores internacionais (OLIVEIRA, 2014, p.96-97).

O conceito de ator internacional é ainda estudado por Rodrigues, que o considera como aquele agente que participa exclusiva e diretamente das relações internacionais (RODRIGUES, 1994, p.13).

De forma objetiva, não existem apenas Estados na sociedade internacional, mas uma série de outros atores que protagonizam o cenário internacional. Em outras palavras, o conceito de ator internacional é amplo, e, assim, abrange não somente o Estado - considerado o principal e mais tradicional ator no cenário internacional -, mas, sim, organizações internacionais, empresa transnacionais, redes, coalizões, grupos e comunidades internacionais, e, ainda de forma excepcional, o indivíduo (OLSSON, 2007, p. 285).

A tipologia estabelecida pelas categorias de ordem binária - atores estatais e não estatais - inicia-se na obra de Phillip Taylor. Para ele, não é viável estabelecer uma lista exaustiva dos inúmeros atores não estatais em virtude das múltiplas funções e objetivos de ordenm econômica, de segurança, política e cultural-ideológica. Nesse sentido, os papeis específicos dos autores internacionais contemporâneos não estatais oscilam na arena internacional em categorias muitas vezes de difícil rotulação porque variam em atuações, capacidades, influência no processo de tomada de decisão, e, ainda, em outros aspectos, nos

Revista Brasileira de Direito Internacional le-SSN: 2526-0219| Curitiba | v. 2 | n. 2 | p. 118 - 134 Jul/Dez. 2016. 
quais a unidade de sistema internacional exerce influência e goza de certa autonomia (TAYLOR, 1984 p.20-22).

Justifica Oliveira (2016) que a tecnologia da informação permitiu a transposição de barreiras geográficas e políticas, incitando a proliferação de entidades que dominam recursos materiais e ideacionais com estrutura de governança descolada do modelo do Estado moderno. No presente, os atores não estatais são exemplos dessa relevância no cenário político global.

A noção e a classificação dos atores não estatais evolui paralelamente com as mudanças aceleradas da sociedade contemporânea, fazendo com que os lamentáveis problemas decorrentes desse efeito acelerado tornem o Estado - ator tradicional das relações internacionais - impotente ou, pelo menos, enfraquecido. Isso justifica a premissa de que o clássico ator estatal passou a depender da atuação funcional dos atores não estatais (OLIVEIRA, 2014, p.108).

Em sua própria realidade social, o Estado desempenha sua função como unidade política, ao lado dos demais atores não estatais, num emaranhado de diversificadas relações gravitacionais da sociedade internacional contemporânea, e todos abastecidos na teia da rede de redes. Os atores não estatais projetam-se calçados pela rede para além dos limites do próprio Estado, e seu papel funde-se ao fenômeno mutante da sociedade (OLIVEIRA, 2014, p.56).

Nessa linha, Oliveira (2016, p.65) considera ainda que, muito embora a realidade da sociedade contemporânea encontre-se dia a dia mais integrada e permeada por atores não estatais, esses agentes não dispõem de um estatuto jurídico que os reconheça em sua subjetividade, requisito que se faz necessário para qualificá-los formalmente como sujeitos de Direito Internacional. Nesse sentido, a práxis internacional tem reconhecido aos determinados atores não estatais a destinação de certos direitos e obrigações internacionais.

Sob a égide de subdivisão binária dos atores internacionais, aos tradicionais atores não estatais, existem os pacíficos (corporações, empresas transnacionais e organizações internacionais não governamentais, por exemplo) e violentos (organizações criminosas e terrorismo, por exemplo). Para exemplificá-los, entende-se que os de índole pacífica são constituídos por agentes de ação cívica e perfil humanista, estruturam-se em redes sociais, em favor de seus objetivos, procurando consolidar e apoiar entre si as mais diferentes iniciativas pacifistas. Os pacíficos são denominados luminosos pelas suas características de paz, 
humanismo e cooperação (OLIVEIRA, 2016, p. 69-77).

Já os de natureza violenta, portadores de interesses escusos e perigosos, representam grandes riscos contra a segurança dos povos e suas nações como um todo, conhecidos como obscuros pelos seus traços de agressão, conflito e destruição. Constituem-se em organizações criminosas e terroristas, de catastróficas consequências (OLIVEIRA, 2016, p. 77).

O conceito de tráfico de pessoas utilizado aqui é o ratificado internacionalmente e define essa atividade como:

\footnotetext{
"o recrutamento, o transporte, a transferência, o alojamento ou acolhimento de pessoas, recorrendo à ameaça ou ao uso da força ou a outras formas de coação, ao rapto, à fraude, ao engano, ao abuso de autoridade, à situação de vulnerabilidade, ou à entrega ou aceitação de pagamentos ou benefícios para obter o consentimento de uma pessoa que tenha autoridade sobre outra para fins de exploração" (ONU, 2007).
}

De acordo com o estudo da Organização Internacional do Trabalho (2006), as mulheres pobres, negras, desempregadas e jovens são as mais vulneráveis ao trabalho forçado ou à exploração, estando também mais expostas, nas migrações entre os Estados, ao abuso e à violência.

Garrafa e Pessini (2003) entendem que as pessoas vulneráveis são aquelas pessoas incapazes, relativa ou absolutamente, de proteger seus próprios interesses. Para eles, as pessoas vulneráveis têm seu poder, inteligência, educação, recursos e forças insuficientes para reagirem propositivamente, diante das possibilidades de exposição a violência, e, neste caso, ao tráfico. Sob a lógica capitalista, a violência tornou-se mercadoria, cuja produção, consumo e comercio geram lucros não só para as organizações criminosas, mas, paradoxalmente, produzem receitas para o aparato estatal com programas e serviços de enfrentamento desses atores não estatais violentos.

O tráfico de pessoas beneficia diretamente o trabalho escravo, a exploração sexual comercial, o casamento servil, o tráfico de órgãos e tecidos humanos. Conforme dados do Fundo de População das Nações Unidas (UNFPA), existem hoje milhões de pessoas migrantes, entre os quais se estima que a metade está em situação irregular nos países-destino. Assim, pode-se perceber que o processo migratório em rede é um celeiro farto para o exercício do poder dos atores não estatais violentos que, voltados a lógica do trafico de pessoas, descartam os indivíduos vulneráveis que não sejam mais úteis como fonte de 
produção de recursos.

Infelizmente, o Brasil é exportador de pessoas e também importador para as mais diversas funcionalidades de utilização de seres humanos, desde seu descobrimento no século XV. Em contraponto, o Estado apenas tardiamente constituiu a Política Nacional de Enfrentamento ao Tráfico de Pessoas (Decreto n. 5498/2006), que é a proposição brasileira de atender ao Protocolo de Palermo, ou seja, o protocolo adicional à Convenção das Nações Unidas contra o Crime Organizado Transnacional relativo à prevenção, repressão e punição ao tráfico de pessoas, com o propósito de enfrentar essa faceta do crime organizado de maneira eficiente e segura.

Mas o crescimento do número de atores internacionais não estatais violentos influentes na sociedade contemporânea, como as organizações criminosas, vem fragmentar o poder soberano dos Estados, ao se utilizarem do processo migratório em rede como uma via de acessibilidade ao alcance de seus objetivos ilícitos.

Desse modo, os atores não estatais pacíficos e violentos, quando estruturados em densas e expansivas redes, deslocam o lugar do poder, limitando e fragmentando a soberania e o estatocentrismo, uma vez que, quando interconectados, operam com maior facilidade e eficiência do que os tradicionais e hierárquicos agentes estatais (OLIVEIRA, 2016, p. 77).

Os atores não estatais - pacíficos e violentos - estão conduzindo as Relações Internacionais do mundo a desconhecidas e complexas direções. As inusitadas descobertas da denominada Revolução Tecnológica Informacional e o uso intensificado da rede mostram-se instrumentos suficientes para o reconhecimento do destacado protagonismo do poder e de influência alcançados por esses agentes (OLIVEIRA, 2016, p. 39-41).

No quadro contemporâneo, o processo migratório em rede, como será tratado a seguir, torna-se uma via aberta para os atores não estatais violentos promoverem o mercado negro à revelia do Estado, exercendo o poder através de uma governança sem governo. De acordo com o alcance de seus propósitos ilegais, mais inusitados, pode-se afirmar que os atores não estatais violentos atuam nas várias expressões de violência e desrespeito aos direitos humanos.

\section{PROCESSOS MIGRATÓRIOS EM REDE}

Revista Brasileira de Direito Internacional le-SSN: 2526-0219| Curitiba | v. 2 | n. 2 | p. 118 - 134 | Jul/Dez. 2016. 
Hodiernamente, as migrações internacionais ainda são parte integrante do desenvolvimento (DE HASS, 2005) e refletem, cada vez mais, papel importante nos mercados de trabalho, nas sociedades de emigração/imigração, nos fluxos financeiros, na mobilidade da força de trabalho e na divisão internacional do trabalho (SASSEN, 1991, p.113-138).

A necessidade de diferentes olhares para as escalas e arranjos transnacionais decorre da diversidade de situações migratórias que sistematizam a complexidade do fenômeno e fortificam a tendência de configuração de espaços da migração nas fronteiras territoriais, onde esses espaços de fluxos precipuamente acontecem (CASTELLS, 1999).

Em decorrência da velocidade tecnológica, os processos urbanos assumem novas formas no dinamismo migratório, apontando seus "mecanismos de desencaixes" (GIDDENS, 1991), transformando o sentido dos fluxos migratórios nacionais e internacionais diante de diferentes espaços e produções locais que passam a responder ao mercado global. Com novos nuances em termos de atividade econômica e de redistribuição espacial da população, portanto, os movimentos migratórios recebem novas compreensões, como, por exemplo, a figura do "trabalhador do conhecimento", o qual constitui o migrante com mão de obra qualificada e usualmente disputada (CASTELLS, 1999).

Para Giddens (1991), os "mecanismos de desencaixes" servem para desenhar os elegidos espaços urbanos. São nesses espaços que o processo de reestruturação urbana se conecta em diferentes escalas (SASSEN, 1991, p.113-138).

A necessidade do reconhecimento de uma melhor compreensão do fenômeno da distribuição e movimentação da população entre os espaços urbanos tem mobilizado governos, instituições, organismos internacionais e universidades, diante da sua complexidade e de seu impacto tanto no pais-destino quanto nos países de origem. As análises de Sayad (1999), para o qual o processo migratório constitui um fato social completo, em que a imigração e a emigração fazem parte de um mesmo processo social, demonstram a dupla experiência social da migração.

O desemprego, o subemprego, o crescimento de trabalhos realizados em casa e as industrias domésticas são exemplos típicos dos efeitos sociais da reestruturação produtiva que alcança os espaços nacionais. A reestruturação das atividades econômicas do processo global provoca alterações expressivas e diretas no âmbito urbano, social e cultural dos países centrais e periféricos (SASSEN, 1991).

Revista Brasileira de Direito Internacional le-SSN: 2526-0219| Curitiba | v. 2 | n. 2 | p. 118 - 134 | Jul/Dez. 2016. 
A mão de obra barata em trabalho degradante e/ou escravo pertence ao contexto da globalização dos mercados de produção e de consumo, o que fomenta o crescimento da imigração irregular que fica subjugada a redes criminosas de tráfico de pessoas e contrabando de imigrantes. A Organização das Nações Unidas estima que mais de cinco milhões de pessoas migrantes são vitimas das redes organizadas de tráfico que faturam bilhões de dólares por ano.

$\mathrm{Na}$ Convenção de Palermo, três protocolos foram assinados, considerando a vulnerabilidade dos migrantes diante de atores não estatais violentos: (a) o Protocolo para Prevenir, Suprir e Punir o Tráfico de Pessoas, especialmente mulheres e crianças; (b) o Protocolo contra o Contrabando de Imigrantes por terra, ar e mar; e (c) o Protocolo contra Fabricação Ilegal e Trafico de Armas de fogo inclusive peças, acessórios e munições.

O direito a migração é constitucional, legitimado e normatizado em acordos nacionais e internacionais. $\mathrm{O}$ direito de ir e vir respalda-se no ideário das políticas internacionais de cooperação e direitos humanos. Nesse sentido, afirma Sassen (1991) que as migrações internacionais também refletem e compõem a reestruturação dos contextos urbanos, do local da produção e sua consequente expansão terceirizada, uma vez que as relações entre o local e o global podem ocorrer de diversas formas sem que haja hierarquia entre os níveis.

Essas analises nos conduzem à compreensão dos processos migratórios internacionais em um determinado território, baseado no "nacionalismo metodológico" (GLICK-SCHILLER, 2007), ou, como salienta Sassen (1991, p. 113-138), no denominado "estatismo enraizado". O "nacionalismo metodológico" refere-se ao pertencimento dos indivíduos a determinados Estados-nação, corroborando as perspectivas que construíram as categorias como estrangeiro. As migrações internacionais transitam em campos sociais transnacionais, razão pela qual Glick-Schiller (2007) aponta para a necessidade de uma mudança no paradigma da assimilação para o do transnacionalismo, nos estudos sobre a migração.

Nesse sentido, a relação entre migração e mudança social deve compor a compreensão dos fenômenos migratórios atuais. Nos espaços migratórios construídos a partir de nexos transnacionais, despontam os desafios teórico-metodológicos para explicações e análises das migrações de imigrantes internacionais qualificados, indocumentados, refugiados, asilados e deportados.

Revista Brasileira de Direito Internacional le-SSN: 2526-0219| Curitiba | v. 2 | n. 2 | p. 118 - 134 | Jul/Dez. 2016. 
As modalidades de migração contemporânea trazem à baila as dimensões transnacionais (GLICK-SCHILLER, 2007). De Hass (2005) enfatiza a necessidade de se reconhecer, nos movimentos migratórios internacionais da atualidade, a sua transnacionalidade, possibilitando os migrantes e suas famílias viverem transnacionalmente e adotar identidades transnacionais. Explicar as migrações internacionais com a incorporação dos desafios do enfoque transnacional significa assumir discursivamente as heterogeneidades e complexidades dos processos migratórios.

Para buscar entender o fenômeno migratório, aquele que transcende as fronteiras do Estado-Nação, Tarrius (1993) agrega a seu debate a expressão "territórios circulatórios", que são os novos espaços da migração ou os percursos dos migrantes. A dificuldade em estabelecer as migrações como temporárias ou permanentes depende da percepção subjetiva do migrante e do sentimento de pertencimento espacial, o que demanda uma nova formulação de conceitos. Courgeau (1973), por sua vez, esclarece que essa dificuldade de estabelecer uma mobilidade temporária ou de longa permanência exige a definição da porção do espaço onde os migrantes desenvolvem suas atividades.

É sob esse paradigma que estão baseadas as políticas para as migrações internacionais: no processo de assimilação dos imigrantes na sociedade receptora e no controle dessa população no Estado-Nação. Tais políticas seguem estatutos de legalização e proteção jurídica a estrangeiros, concedendo, quando assim o fazem, meramente direitos restritos.

Essa possibilidade de mobilização nas migrações internacionais recentes parece ter seu caminho nas redes sociais, gerando redes de informação que não só conectam lugares de origem e de destino, como também permitem nos países de destino a (re)criação de redes nos espaços sociais dessa imigração (MASSEY et al, 1993).

Truzzi (2008) entende que é por meio de vínculos que se estabelecem no período de integração à nova sociedade, a partir de padrões residenciais, ocupacionais, matrimoniais e das associações étnicas, que se institui a função estratégica das redes na sociedade receptora.

Para Williams (2003, p. 94), as redes sociais refletem o caráter dos laços mantidos na rede e com a rede e ao modo como ela funciona, e como cria oportunidades ou restrições para os agentes que dela fazem parte. Nesse aspecto, as redes sociais presentes nos processos migratórios podem abrir possibilidades de mobilização, do direito à associação e à informação, criando mecanismos que conduzam à garantia dos direitos humanos. 
Na perspectiva do direito como fruto da convivência coletiva, ressalta-se o espaço público e o direito de associação, que constituem dois elementos centrais em que os direitos humanos podem ser relacionados com as redes sociais da imigração. Como lembra Arendt (1987), o acesso ao espaço público garantirá o direito de pertencer a uma comunidade política.

Ao mesmo tempo em que se transformam as dimensões sociais, novas formas do espaço denunciam que a constituição de poderosas organizações transnacionais, ligadas por redes e subordinadas e descentralizadas, é fator decisivo no processo migratório em rede porque confere sentido estrutural para cada território (CASTELLS, 1999).

A intangibilidade e a onipresença das redes na organização social, simultaneamente, transpõem espaços e cenários, passando a existir invisivelmente em todas as partes e lugares do mundo (WILLIAMS, 2003, p.92). Independentemente de se adentrar na tipologia das redes, as redes tecnológicas, ao facilitarem os fluxos de informação, conhecimento e comunicação, acabaram por abrir espaço para além das organizações empresariais de negócios virtuais, e viabilizaram a atuação de redes sociais maiores e dispersas (ARQUILLA e RONFELDT, 2003).

Segundo Williams (2003, p.91-95), as redes "variam em tamanho, forma coesão, domínio e propósito. Podem apresentar-se grandes ou pequenas, locais ou globais, domésticas ou transnacionais, lógicas ou difusas, centralizadas ou descentralizadas, com propósitos fixos ou sem direções".

Castells (1999) observa que a rede pode ser entendida como um conjunto de nós interconectados, apresentando estrutura aberta, especialmente dinâmica, como capacidade de expandir-se forma ilimitada e constituir as denominadas redes de redes. A constituição de poderosas organizações transnacionais, ao mesmo tempo que promove sentido estrutural para cada território, também transforma as dimensões sociais e novas formas do espaço ligadas por redes subordinadas e descentralizadas, e ainda revela os fatores decisivos no processo migratório em rede.

O desenho de redes autônomas e descentralizadas construídas nas inter-relações dos atores não estatais violentos prova não só a sua emergente atuação na rede, mas também a existência de múltiplas estruturas organizativas de grande mobilidade que se unem para satisfazer seus objetivos ilícitos (OLIVEIRA, 2016, p. 54-77).

Com isso, a finalidade das redes para facilitar os fluxos de informação, conhecimento

Revista Brasileira de Direito Internacional le-SSN: 2526-0219| Curitiba | v. 2 | n. 2 | p. 118 - 134 | Jul/Dez. 2016. 
e comunicação é aumentar a eficiência das organizações empresariais e dos negócios virtuais, sejam eles lícitos ou ilícitos. As evidências empíricas das migrações internacionais em rede demonstram a complexidade e a heterogeneidade da imigração internacional neste século.

Assim, os desafios para o processo migratório em rede no século XXI implicam em revisões conceituais acerca das novas mobilidades, modalidades e explicações desse fenômeno social. Ao ser afetada pelo poder dos atores não estatais violentos e seu exercício de governança sem governo, a migração é dominada por arranjos multidirecionais complexos das relações internacionais contemporâneas.

\section{O PODER DOS ATORES NÃO ESTATAIS VIOLENTOS NO PROCESSO MIGRATÓRIO EM REDE}

A análise da evolução histórica do estudo do poder encontra amparo nas contribuições de pensadores como Aristóteles, Maquiavel, Hobbes, Locke e Weber, clássicos estudiosos das relações de poder, ao lado de autores contemporâneos como, por exemplo, Foucault, Hannah Arendt e Talcott Parsons, dentre outros.

O conceito de poder percorreu os mais diversos momentos históricos, desde o homem como "animal político" que fala, qualificado por Aristóteles (1996, p. 13), ao homem que utiliza mecanismos de aquisição e manutenção desse poder a partir de uma perspectiva prática, apontada por Nicolau Maquiavel (1988, p. 3). Ainda justificou os postulados de Hobbes (1957, p. 64), ao considerar o poder como um desejo da natureza do homem, e as ideias trazidas por John Locke (1957, p. 74), de associação do poder a um estado de sujeição que seja regulado por legitimas instituições para limitar o tal "estado de natureza". Mais adiante, em Max Weber (1980, p.531), o poder decorre da autoridade ou dominação que pode ser exercida mesmo por meio da violência, que, no âmbito do Estado, se evidencia como a "violência legítima".

Em linhas gerais, essa ideia prevalecente de poder associa o fenômeno com expressões correntes, como o "monopólio da violência legitima" relacionado ao conceito de governança exercida por autoridade publica em que governo e governança, unidos, abraçam o poder do Estado "sobre" seus cidadãos, a vontade de um sobre o outro, a ideia de jogos de soma zero (porque o ganho de um é proporcional a perda do outro) e as convicções proferidas

Revista Brasileira de Direito Internacional le-SSN: 2526-0219| Curitiba | v. 2 | n. 2 | p. 118 - 134 | Jul/Dez. 2016. 
pelas teorias de equilíbrio do poder estatal. Em síntese, ela explicita a ênfase dada ao conflito "sobre" o consenso nas relações entre os atores internacionais.

Essa concepção tradicional, resumida na ideia de "poder sobre", configura tipicamente "um exercício de autoridade a sujeitar os outros atores" e se presta como uma condição intrínseca àquele que é detentor de maior poder, estabelecendo, assim, um conflito com aquele detentor de menor poder, ou seja, a parte mais fraca dessa relação. É, portanto, visto como um instrumento de dominação, uma vez que o indivíduo detentor de poder faz com que o outro se submeta à sua vontade (OLSSON, 2014, p. 147-148).

Por outro lado, desvinculados de valores nacionais, sociais e ambientais, o poder das entidades privadas é relacionado ao exercício de uma autoridade privada de fundo econômico, que exerce a governabilidade de maneira estratégica, declarando sua preferência pelo consenso "para" evitar o conflito. O chamado "poder para", por exemplo, é estudado por autores como Hannah Arendt (1970) e Talcott Parsons (1967).

Sabe-se que o processo de globalização neoliberal, somado aos recursos de telecomunicações e informática, aproximaram os mercados e interligaram a produção capitalista global à racionalidade econômica apátrida (que se furta aos marcos regulatórios estatais), em prol exclusivamente do lucro. O poder econômico nas relações globais, então, é o mais utilizado e cobiçado pelos atores não estatais, não só para a manutenção de seu protagonismo neste início de século XXI, mas, também, pela realização do propósito ao qual se destinaram.

No universo dos atores emergentes, os atores não estatais são os atuais protagonistas das relações internacionais da sociedade em rede, e sua emergência advém substancialmente do exercício de poder econômico que concede a eles certa autonomia, ao influenciar, liderar e até condicionar decisões dos atores estatais (OLIVEIRA, 2014, p. 110). Embora existam atores não-estatais sem propósito econômico (como as organizações internacionais nãogovernamentais, por exemplo), estes são uma notável exceção no universo de corporações transnacionais e organizações criminosas globais.

A modalidade de governança sem governo é aquela em que o exercício de poder na sociedade em rede é realizado e instrumentalizado por esses atores não estatais emergentes. $\mathrm{O}$ poder, nessa situação, combina a remanescente ordem vertical tradicional calcada no Estados e suas derivadas organizações internacionais intergovernamentais com a ordem horizontal dos

Revista Brasileira de Direito Internacional le-SSN: 2526-0219| Curitiba | v. 2 | n. 2 | p. 118 - 134 | Jul/Dez. 2016. 
novos atores e protagonismos fomentados pela "redes de rede", gerando, assim, uma concorrência entre eles no plano global (OLIVEIRA, 2016, p. 105).

Pode-se afirmar que os atores não estatais violentos, detentores do "monopólio da violência" agora "ilegítima", quando atuantes no processo migratório em rede, exercem seu poder ao condicionar o dominado à ilusão coletiva capaz de reconhecer sua liderança, como um governo legitimo àquele exercício.

De acordo com pesquisas promovidas pelo Ministério da Justiça (BRASIL, 2008), há quadrilhas organizadas que capturam jovens mulheres para realizarem serviços sexuais e trabalho escravo no âmbito das redes de tráfico e exploração para países europeus. É oportuno comentar, também, que essas quadrilhas, além de explorarem sexualmente as vitimas, em alguns casos as submetem a remoção de seus próprios órgãos. O Brasil está entre os principais países em desenvolvimento que exportam mulheres (LEAL, 2008).

Essa situação fática constitui exemplo de situação desencadeadora de uma governança distanciada do governo, que não é exercida nem por autoridade publica, tampouco por autoridade privada lícita (como uma corporação transnacional), mas, estrategicamente planejada a ser exercida por autoridade privada ilícita, com capacidade de governança sem governo, ao afetar a efetividade das políticas publicas promulgadas pelo Estado ou seus derivados.

O Escritório das Nações Unidas contra Drogas e Crime reconhece que um dos pontos mais deficitários do enfrentamento ao tráfico de pessoas, não apenas no Brasil, é a questão da atenção às vitimas. Nesse sentido, o Ministério da Saúde, a Secretaria de Políticas para as Mulheres e o Ministério do Desenvolvimento Social esforçam-se para incorporar o tráfico de pessoas como uma das formas de violência a serem detectadas e tratadas pelo Estado. A escassez de políticas de prevenção e assistência à saúde das vitimas do trafico de seres humanos eleva o poder dos exploradores sobre os trabalhadores migrantes em situação irregular e reforça o medo das vitimas em procurarem apoio de instituições governamentais porque temem receber sanções como a extradição (ONU, 2007).

Em outras palavras, a vulnerabilidade das vitimas é o termômetro da intensidade do poder compulsório lançado pelos atores não estatais violentos sobre elas. O tráfico de pessoas está no cotidiano como um crime silencioso, que retira a dignidade do ser humano, deixandoo completamente vulnerável. O "poder sobre" dessas organizações criminosas é exercido no 
processo migratório em rede, recaindo sobre o individuo vulnerável, através do fluxo multicêntrico e de típica governança sem governo.

Tal cenário, interconectado por seus "nós", faz-se realidade na atual sociedade global, o que demanda respostas às implicações de poder desses emergentes atores não estatais violentos, em razão dos riscos de seu impacto social, político e econômico para as futuras gerações.

\section{CONSIDERAÇÕES FINAIS}

A medida do desenrolar dos acontecimentos fumegantes da história mundial do século XX, com guerras, epidemias, perseguições, catástrofes e uma série de motivos intolerantes, impulsionaram milhões de pessoas a viverem em condições transitórias, no âmbito do processo migratório. O processo migratório, até então inerente à história da humanidade, transforma-se em sua complexidade ao assumir novas vias no deslocamento humano.

Não é equivocado entender que, para imigrar, é preciso uma ação anterior do agente, a ação de emigrar. Como polos estruturantes do processo migratório, as teorias que o abordam, em sua maioria, são teorias econômicas que observam o impacto de "custos e vantagens" dessas transferências humanas.

Hodiernamente, porém, as migrações internacionais instigam a repensar as hierarquias nas quais as migrações e os migrantes têm sido analisados. Sua face mosaica dentro da análise política, cultural, economia e social perfaz uma nova rota para vias convidativas de exercício do poder pelos atores não estatais violentos que impõem sua vontade, desafiando a soberania dos Estados.

A inserção dos atores não governamentais violentos no protagonismo do processo migratório foi alicerçada pela poderosa rede, alimentada pela globalização e instrumentalizada para garantia da ilusão coletiva de "ordem pública”, gerenciada pela figura do Estado.

Antagonizando com os atores não estatais pacíficos, o que se estabelece é que ambos os atores utilizam-se das mesmas vias para alcançar seus objetivos, o que demonstra que a intenção do ator é elemento a ser apreciado no contexto jurídico. A ineficiente proteção legal dada ao emigrante, a fragilidade humana inerente ao deslocamento e as barreiras culturais e linguísticas, por sua vez, promovem terreno fértil para protagonismo dos atores não estatais violentos, que se beneficiam das patologias sociais e transtornos mundiais.

Revista Brasileira de Direito Internacional le-SSN: 2526-0219| Curitiba | v. 2 | n. 2 | p. 118 - 134 | Jul/Dez. 2016. 
Como peças dinamicamente atuantes em cenários diferentes, tais atores internacionais dispõem de informação e interesse, somadas ao lucro, poder e acessibilidade, e os direcionam de acordo com suas prioridades. Por sua vez, seus instrumentos promovem paradoxos jurídicos, políticos e sociais que desafiam as promessas de paz e equilíbrio do poder.

Por fim, cabe notar que o processo migratório em rede, quando amoldado pelo poder político dos atores não estatais violentos, demonstra-se como um eficiente instrumento de passagem de fluxos transnacionais na mais ampla das acepções da palavra. Essa passagem, porém, é utilizada para a expansão de poder e práticas voltadas ao enriquecimento ilícito, o que recomenda a urgente atenção de toda a sociedade contemporânea para prevenir, ou, ao menos, minorar os seus nefastos efeitos para as gerações futuras.

\section{REFERÊNCIAS}

ARENDT, Hannah. A condição humana. Tradução de Roberto Raposo. 3 ed. São Paulo: Forense Universitária, 1987.

ARQUILLA, John; RONFELDT, David. Redes y Guerias em red: el future del terrorismo, el crimen organizado y activismo politico. Madrid: Alianza Editorial, 2003.

ARISTÓTELES. The politics and the constitution of Athens. Edited by Stephen Everson. Revised student edition. Cambridge: Cambridge University Press, 1996.

BRASIL, Ministério da Justiça. Secretaria Nacional de Justiça. Política nacional de enfrentamento ao trafico de pessoas. Brasília: SNJ, 2008.

CASTELLS, Manuel. A sociedade em rede. Tradução Roneide Venâncio Majer. São Paulo: Paz e Terra, 1999.

COURGEAU, D. Migrants et migrations. Population, New York, n.1, 1973.

COURGEAU, D. Nuevos enfoques para medir la movilidad espacial interna de la población. Notas de Población, Santiago de Chile, CELADE, v. 17, n.50, 1990.

DE HASS, Hein. International migration, remittances and development: myths and facts. Third World Quarterly, 2005, p. 1269-1284.

GARRAFA, Volnei; PESSINI, Leo. Bioética: poder e injustiça. São Paulo: Loyola, 2003.

GIDDENS, Anthony. As consequências da modernidade. Trad. Roberto Machado. São Paulo: Editora UNESP, 1991.

Revista Brasileira de Direito Internacional le-SSN: 2526-0219| Curitiba | v. 2 | n. 2 | p. 118 - 134 | Jul/Dez. 2016. 
GLICK-SCHILLER, N. The centrality of ethnography in the study of transnational migration - seeing the wetland instead of the swamp. In: SAHOO, A. Kumar; MAHARAJ, B. Sociology of Diaspora. India: Rawat Publications, 2007, p. 118-155.

HOBBES, Thomas. Leviathan: or the matter, form and power of a commonwealth ecclesiasticall and civil. Ed. with an introduction by Michael Oakeshott. Oxford: Basil Blackwell, 1957.

LEAL, M. F. Pesquisa sobre o trafico de mulheres, crianças e adolescentes para fins de exploração comercial no Brasil (Pestraf): Relatório Nacional (Brasil.), CÉCRIA, 2008.

LOCKE, John. Two treatises of government. 2ed. Critical edition with an introduction and apparatus criticus by Peter Laslett. Cambridge: Cambridge University Press, 1957.

MAQUIAVEL, Nicolau. The Prince. Edited by Quentin Skinner and Russell Price. Cambridge: Cambridge University Press, 1988.

MASSEY, D. et al. Worlds in motion: understanding international migration at the end of the millenium. Clarendon: Press Oxford, 1993.

OLIVEIRA, Odete Maria de. Relações internacionais, direito e atores não estatais: delineamentos de fundamentação. In: OLIVEIRA, Odete Maria de (Org.). Relações internacionais, direito e poder: cenários e protagonismos dos atores não estatais. Volume I. Ijuí: Ed. Unijuí, 2014, p. 33-131.

O protagonismo dos atores não estatais pacíficos e violentos: a revolução da rede de redes. In: OLIVEIRA, Odete Maria de (Org.). Relações internacionais, direito e poder: atores não estatais na era da rede global. Volume III. Ijuí, Ed. Unijuí, 2016, p.39-86.

OLSSON, Giovanni. O poder político no espaço global: o protagonismo dos atores estatais e não estatais. In: OLIVEIRA, Odete Maria de (Org). Relações internacionais, direito e poder: cenários e protagonismos dos atores não estatais: volume I. Ijuí: Unijuí, 2014, p.133177.

Poder político e sociedade internacional contemporânea: governança global com e sem governo e seus desafios e possibilidades. Ijuí: Ed. Unijuí, 2007.

ORGANIZAÇÃO INTERNACIONAL DO TRABALHO. Tráfico de pessoas para fins de exploração sexual. Brasília, 2006.

ORGANIZAÇÃO DAS NAÇÕES UNIDAS. Escritório da Nações Unidas contra drogas e crime. A iniciativa global contra o tráfico de pessoas (S.I), 2007.

PARSONS, Talcott. Sociological theory and modern society. New York: The Free Press, 1967.

Revista Brasileira de Direito Internacional le-SSN: 2526-0219| Curitiba | v. 2 | n. 2 | p. 118 - 134 | Jul/Dez. 2016. 
RODRIGUES, Gilberto Marcos Antônio. O que são relações internacionais. São Paulo: Brasiliense, 1994.

SASSEN, Saskia. The global city: New York, London, Tokio. New Jersey: Princeton University Press, 1991.

SAYAD, A. La Double absence: dês ilusions de l'emigré aux sou frances de l'immigré. Paris: Seul, 1999.

TAYLOR, Phillip. Non-State Actors in International Politics: from transregional to substate organizations. Boulder: Westview Press, 1984.

TARRIUS, A. Territoires circulatoires et espaces urbains: différenciation des groupes migrants. Annales de la Recherche Urbana. n.59-60, 1993, p.50-59.

TRUZZI, O. M. S. Redes em processos migratórios. Tempo Social - Revista de Sociologia da USP, v.20, 2008, p. 199-218.

WEBER, Max. Wirtschaft und Gesellschaft. Fünfte revidierte Auflage. Tübingen: Tübingen/Mohr, 1980.

WILLIAMS, Phil. Redes Transnacionales de delincuencia. In: ARQUILLA, John; RONFELDT, David. Redes y Guerias em red: el future del terrorismo, el crimen organizado y activism político. Madrid: Alianza Editorial, 2003, p. 88-123. 